\title{
Governance-Management-Performance (GMP) Framework: A Fundamental Thinking for Improving the Management Performance of Public Projects*
}

\author{
Yaling Du, Yilin Yin \\ School of Management, Tianjin University of Technology, Tianjin, China. \\ Email: tdduyaling@126.com
}

Received April 30 ${ }^{\text {th }}, 2010$; revised June $3^{\text {rd }}, 2010$; accepted July $8^{\text {th }}, 2010$.

\begin{abstract}
Public projects play an active role in the development of economy. However, public project management performance $(P P M P)$ is not very satisfying and urgent to be improved, especially in China which is in its flourishing period of public project investment and construction nowadays. The purpose of this paper is to propose and theoretically test a fundamental thinking for the government to improve PPMP. In this study, project management (PM) and project governance $(P G)$ are identified to be the controllable factors which affect PPMP greatly through a thorough literature review. In order to bring PG, PM and PPMP into a whole system, SCP paradigm is applied properly to the agency industry of public project and, as a result, GMP framework for the analysis of public project is presented through exhaustive ratiocination. Subsequently, GMP framework is broken down into three parts and each part is testified theoretically to ensure the reliability of GMP framework. The findings indicate that there are two approaches to improve PPMP, i.e. PG and PM, and PG seems to be more effective in China due to its vast development space.
\end{abstract}

Keywords: Public Project, Management Performance, Project Management (PM), Project Governance (PG), GMP Framework

\section{Introduction}

Nowadays, it is the basic function of each country's government to provide a wide and diverse range of public services, such as hospitals, roads, schools, prisons, etc [1]. Public project which can produce public goods for the community is the crucial way for the governments to carry out the tasks of public service. With the rapid development of economy, the government of every country in the world meets the challenges of delivering public services urgently with growing expectations from the users. On the other hand, faster economic growth makes the government have the ability to raise adequate capital for more and more public projects. Therefore, public projects play an active role in the economic life of every country, especially in China which adopts an active fiscal policy again ${ }^{1}$ to resist the adverse effect of financial crisis in 2008 [2].

\footnotetext{
*Sponsored by National Nature Science Foundation under Grant No.
} 7077 2058/G0213.
The central government of China attempts to promote its economy through increasing the investment in fixed assets and this measure brings mass public projects [3]. It seems that China is in its flourishing period of public project investment and construction at present. However, the management performance of public project in China is not very satisfying. According to China Statistical Yearbook [4], the investment error rate of the newly increased fixed assets in urban area is always high, even above $40 \%$, in the last decade. In fact, how to improve the management performance of public project successfully grasps increasing attention in both theory and practice all over the world.

The objective of this paper is to explore the for mation mechanism of public project management performance (PPMP) so as to present a fundamental think-

\footnotetext{
${ }^{1}$ China conquered the financial crisis that broke out in 1997 by adopting an active fiscal policy from 1998 to 2004. Then it began to carry out a steady fiscal policy from 2005 until the coming of the new financial crisis in the second half of 2008.
} 
ing for improving it. This however requires viewing PPMP in the proper perspective as a first step. It is in this spirit that this paper looks into a myriad of relevant literatures to classify all the factors affecting PPMP and then get the controllable factor grouping, i.e., project management (PM) and project governance (PG). Subsequently, we explore the applicability of SCP paradigm in this study so that we can bring PG, PM and PPMP into the same system. Finally, we deduce the GovernanceManagement-Performance (GMP) framework to public projects and further analyze it deeply.

\section{Literature Review}

In this section, we have to analyze and answer two questions above all, i.e., what is PPMP and what can affect it, in order to improve PPMP effectively. Then we should also investigate the previous researches on the relationship between PM, PG and PPMP to find the breakthrough point.

\subsection{PPMP}

Performance is an ambiguous concept so far, it's uncertain that performance is the results, the behaviors/processes or both in the area of Human Resource Management (HRM) [5]. As to construction project, project/PM performance is rarely defined explicitly and we can only comprehend it according to a lot of literatures that focus on performance evaluation indicators. Traditionally project/PM performance is evaluated using schedule, cost, and quality performances, also known as the 'iron triangle' [6]. Subsequently a number of researchers have proposed different sets of performance evaluation indicators in addition to the iron triangle [7]. A close look at the performance evaluation indicators (e.g. Bryde [8]; Van Truong Luu et al. [9]; Westerveld [10]) would suggest that these could be broadly kept under two broad categories: the indicators reflecting the results of the project and the indicators reflecting the behaviors/processes of PM. The former is just the conventional description of project/PM performance, while the latter is the content of PM. From what has been analyzed above, we deem that project/PM performance is the implementation degree of the project/PM object and it is the measurement of both the processes and the results of PM because the two aspects can not substitute for each other completely. Therefore, project/PM performance has different contents on the different observation points of the project: It includes not only the results on this point but also the process of PM when we investigate during the project or the period of PM because the processes of PM now will determine the results later (for example, when assessing the PM performance of a project, we should consider both the results and the processes); but it includes the results only when we study in the end of the project or the process of PM due to the complete conversion of behaviors/processes into results. This study attempts to rethink the formation mechanism of PPMP and the process of PM is regarded as an independent aspect affecting it (for instance, Florence Yean Yng Ling et al. [11] defined project performance as results only when they investigate the key PM actions affecting it), so it is reasonable to consider the project/PM performance from the view of results only.

Project performance and PM performance are usually used confusedly, but they are absolutely diverse from each other in fact. According to the study of Munns and Bjerimi [12], project performance reflects the whole life cycle of the project (including conception, planning, production/implementation, handover, utilization and closedown), while PM performance is only a part of project performance because it reflects the phases of planning, production/implementation and handover only. What we focus on is PM performance, this means that this study restricts to the construction stage of a public project, i.e., from feasibility study to final acceptance. Moreover, public project differs from private project for its commonweal - goal, so PPMP should emphasize not the economy of the project only but also its efficiency effectiveness and equity (4E for short) [13]. From what has been analyzed above, PPMP is the results of the PM behaviors during the construction stage of the public project and $4 \mathrm{E}$ should be considered when it is evaluated.

\subsection{PM and PG Which Affect PPMP}

PPMP will be improved successfully only if the efforts are made on the proper and correct points. This means that, to improve PPMP, the first problem we have to solve is which factors can affect PPMP greatly and, at the same time, can be controlled by us. Therefore we consulted 124 literatures (including 80 Chinese ones and 44 overseas) about construction project that focus on 'project management performance' or 'project success' (We think that PM success is the comparative best status of PM performance and project success covers PM success like the relationship between project performance and PM performance). The influential factors to PM performance involved in these literatures can be divided into two groupings (see Table 1) [14]. Uncontrollable factor grouping includes factors about the context and human can not change them once the project site is decided. On the other hand, controllable factor grouping includes factors that belong to PM and PG, while both of them are the behaviors and processes of the key project partici- 
pants, so they can be optimized in order to improve the PM performance. The result above is just consistent with the result of reviewing and analyzing mass literatures at home and abroad, i.e., the research paradigm of improving PPMP shifts from management paradigm (its theory system is PM) to economics paradigm (its theory system is PG) due to the dual requirements of theory and practice (shown in Figure 1) [15]. Obviously, this study should focus on PM and PG in order to find the formation mechanism of PPMP.

Every intact contractual organization involves both management and governance [16], so does the public project. It is accepted widely that PM contributes to excellent PM performance directly, while it needs to be confirmed further that PG also has positive effect on PM performance because PG is a new concept proposed just during the $1990 \mathrm{~s}$ and its effect on PM performance is indirect and unclear. PM is the means by which the work of the resources assigned to the temporary organization is managed and controlled to deliver the beneficial change desired by the owner [17]. While PG is a controversial notion and various researchers define it in completely different ways, for example, researchers in the west present it under the framework of Williamson's Transaction
Cost Economics (Turner [18]; Winch [19]), while some researchers in China learn from the concept of corporate governance to define it considering the similarity of corporate and project as contractual organizations [20]. This study aiming at public project holds that PG is the process of establishing an institution framework (the whole project transaction can be accomplished under it) to win success of project management; it defines the rights, responsibilities and interests of the key stakeholders properly in order to construct well order, and then uses various mechanisms to maintain the order. According to the definitions of PM and PG, we can find their distinct differences in public projects shown in Table 2 [21].

\subsection{Their Relationships}

It is indispensable to review the literatures about the relationship between PM, PG and PM performance in order to highlight the innovation of this study.

\subsubsection{Relationship between PM and PM Performance}

PM is first documented during the $1950 \mathrm{~s}$ and 1960 [23] and its origin is to ensure better performance of the project [7]. There's a large amount of literatures that focus on the relationship between PM and PM performance, for example, Florence Yean Yng Ling et al. [11] investi-

Table 1. Groupings of critical influential factors to PM performance in the 124 literatures.

\begin{tabular}{cl}
\hline \multicolumn{1}{c}{ Grouping name } & Content \\
\hline Controllable factor grouping & $\begin{array}{l}\text { Factors that belong to PM, such as strong/detailed plan and clear realistic objectives. } \\
\text { Factors that belong to PG, such as coordination among stakeholders, equal power/empowerment. }\end{array}$ \\
Uncontrollable factor grouping & $\begin{array}{l}\text { Factors about the context, including technology condition, macroeconomic condition, political stability, } \\
\text { culture, climatic condition, strength of legal system and urgency. }\end{array}$ \\
\hline
\end{tabular}

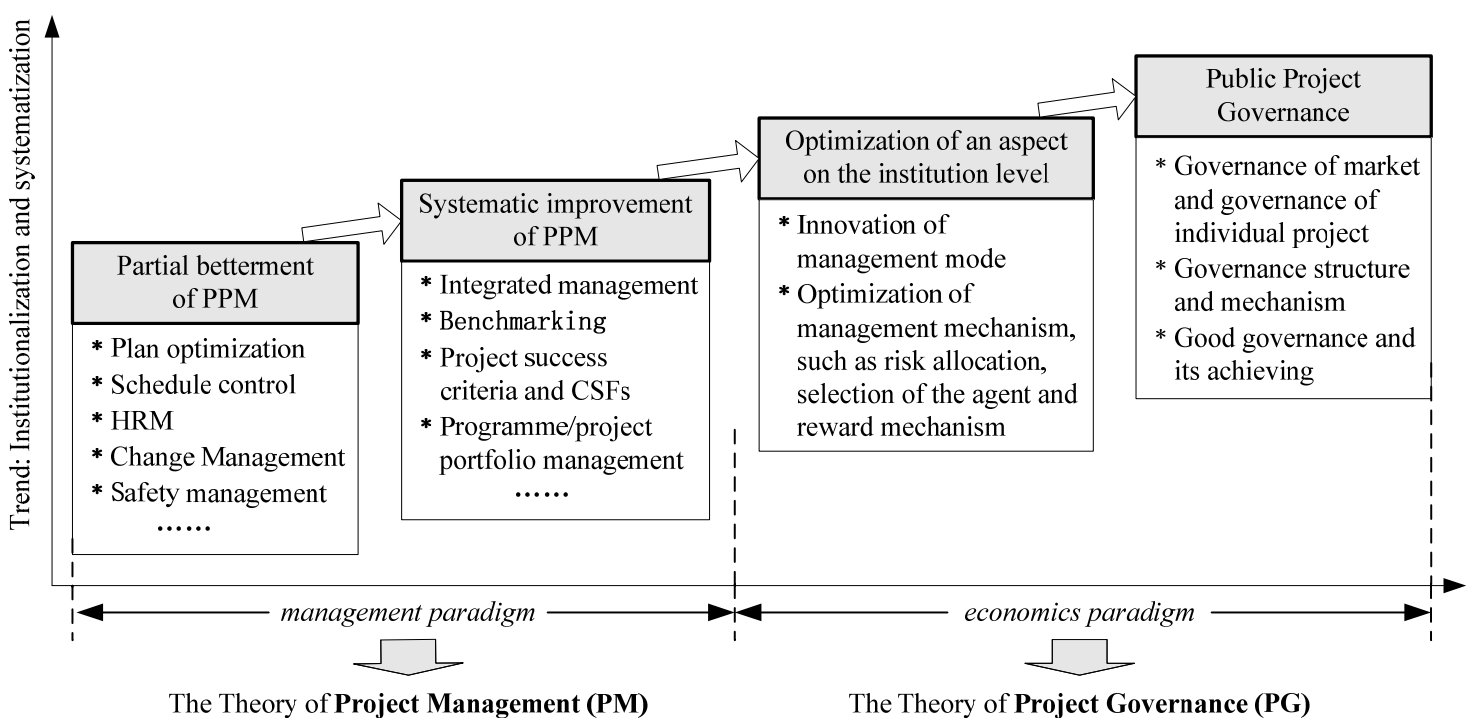

Figure 1. Research paradigm shifting of PPMP improvement. 
Table 2. Differences between PM and PG in public projects.

\begin{tabular}{|c|c|c|}
\hline Items & PM & PG \\
\hline Essence & $\begin{array}{l}\text { Delivering product under the restrictions of cost, time } \\
\text { and quality. }\end{array}$ & Harmonizing all stakeholders and defusing their interest conflicts. \\
\hline Goal & Realizing the targets of cost, time and quality. & Realizing the value of the project. \\
\hline Executor & $\begin{array}{l}\text { The party which manages the project directly, i.e., the } \\
\text { agent. }\end{array}$ & $\begin{array}{l}\text { Involving all the key stakeholders and the government principal is the } \\
\text { steersman. }\end{array}$ \\
\hline $\begin{array}{l}\text { Source of } \\
\text { authority }\end{array}$ & The top manager of the agent. & The participation and interaction of all involved parties. \\
\hline Object & $\begin{array}{l}\text { The resources of the project organization, including } \\
\text { staff, capital, technology and so on. }\end{array}$ & $\begin{array}{l}\text { A set of relationships (i.e., rights, responsibilities and interests) between the } \\
\text { key stakeholders. }\end{array}$ \\
\hline $\begin{array}{l}\text { Effect on } \\
\text { resource }\end{array}$ & $\begin{array}{l}\text { The allocation of resources on the basis of PG } \\
\text { framework and their effective utilization. }\end{array}$ & $\begin{array}{l}\text { The secondary assignation of resource that follows the assignation by the } \\
\text { market. }\end{array}$ \\
\hline Content & $\begin{array}{l}\text { Scope, time, cost, risk, quality, human resources, } \\
\text { communication and procurement management } \\
\text { (according to PMBOK [22]) }\end{array}$ & $\begin{array}{l}\text { 1) Governance of public project market and governance of individual proj- } \\
\text { ect (according to its research level); } \\
\text { 2) Governance structure and governance mechanism (according to the chara } \\
\text {-cter of its content). }\end{array}$ \\
\hline Tools & Management technique/approach/thought. & $\begin{array}{l}\text { Contract, reputation of the agent, credit of the partners, market competition, } \\
\text { relevant laws and regulations. }\end{array}$ \\
\hline Results & $\begin{array}{l}\text { Delivery of qualified product on time within the } \\
\text { budget. }\end{array}$ & $\begin{array}{l}\text { 1) Macroscopic level: building a institutional environment in the market; } \\
\text { 2) Microcosmic level: constructing and then maintaining well order in an in- } \\
\text { dividual project. }\end{array}$ \\
\hline
\end{tabular}

gated PM practices that Singaporean AEC firms adopted in China and the statistical analysis revealed that PM practices are significantly $(\mathrm{p}<0.05)$ correlated with performance metrics.

\subsubsection{Relationship between $P M$ and $P G$}

The relationship between PM and PG has been analyzed by various researchers since the concept of PG came into being. Frank T. Anbari et al. [24] grouped the researches on PM into nine major schools of thought and one of them is the governance school which viewed the project as a temporary organization. Obviously, they believe that PG is subordinate to PM. While most of the researchers in China (Sha Kaixun [25]; Yan Ling and Yin Yilin, 2006 [20]) think that PM and PG belong to the different research paradigms, the former is on the level of operation and the latter is on the level of institution. This paper holds the identical view with them. We believe that different measures should be taken to optimizing PM and PG. In addition, researches discussed the difference between PM and PG, but there's no literature about their effect mechanism, i.e., how PM and PG effect each other.

\subsubsection{Relationship between PG and PM Performance}

A lot of literatures attempted to optimize an aspect of PG to improve the PPMP in recent years, for example, $\mathrm{Li}$ Bing et al. [26] attempted to achieve proper allocation of risk in PPP/PFI construction projects, Robert L K Tiong and Jahidul Alum [27] aimed at selecting a best tender proposal for BOT projects. In addition, Yan Ling and Yin Yilin [28] explored how to evaluate and adjust PG (as a whole) in order to improve the management performance of construction-agent project. Obviously, the positive effect of PG on PPMP is accepted by these researchers without any confirmation. We guess it is due to the following reasons: 1) the positive effect of corporate governance on the company's performance is proved empirically [29], so this conclusion is used in public projects considering their similarity as contractual organizations, but they are different in essence; 2) PG is a new concept and researchers haven't reach agreement on it, this set a obstacle for the work of confirmation; 3) enough data have to be collected for the empirical analysis, but it's more difficult to get enough data about a project (usually through questionnaire survey) than that about a listed company (available from relevant website).

From what has been analyzed above, the research on the relationship between PG and PM/PPMP is the weak part in the area of PPMP improvement. Furthermore, all the previous studies focus on the relationship of two elements among PM, PG and PPMP, while there's no literature which considers all the three at the same time. Against this background, the need for bringing PM, PG and PPMP into a system to explore their relationship is therefore obvious.

\section{Research Method}

It is concluded from literature review that PM and PG can affect PPMP, but their relationships are not very clear. In this study, how they interact with each other will be explored through the employment of the Structure Conduct - Performance (SCP) paradigm, which is the 
classical analysis paradigm in the theory of Industrial Organization. To ensure the validity of the research result, whether SCP paradigm can be applied in the study on public project indeed should be analyzed and answered above all.

\subsection{SCP Paradigm and its Applicable Conditions}

According to SCP paradigm, market structure determines the conduct of the firms in the market and the conduct of the firms determines the market performance, so the government can improve the market structure through relevant industrial organization policies in order to get better market performance [30-31]. Obviously, market structure is the most important element in this framework. SCP paradigm reveals the law of performance formation in an industry so as to help the government take measures to improve the performance of the market. This is just consistent with the intention and thought of this study. However, SCP paradigm is suitable for the researches on an individual industry and there are some requirements should be met by the study objects:

1) SCP paradigm aims at industry, which is a group of enterprises sharing some important characters. The enterprises in the same industry provide similar goods or services and on the same or related value chain [32].

2) Industry exists in the market so that the enterprises in it can do trade to sustain and develop. The market must be steady. It means that the demand and supply in the market are both long-term and steady and the enterprises are all stable contractual organizations.

3) SCP paradigm has its own scope of application, it means that not all the industries can be analyzed using it. In fact, the typical industries that investigated by SCP paradigm are characterized by its oligopoly market, for example, initial researches with SCP paradigm are concentrated in the manufacturing industry with monopolistic character (e.g. mechanical manufacturing, transportation industry and metal manufacturing). Nowadays, although the studies using SCP paradigm are not restricted in manufacturing industry only, they selectively focus on the industries in which the policies of the government play an important role [33]. This is because the origin of SCP paradigm is to help the government seek the policies for better performance of an industry.

4) Enterprise is the basis of the industry. Since SCP paradigm is completely established on neoclassical economics, enterprise is abstracted as a black box that considers the relationship of input and output only and the inside of the enterprise is believed to go smoothly [33]. It means that SCP paradigm analyzes the enterprises from the perspective of production and neglects the institution inside it. This viewpoint also leads to the decline of SCP paradigm because more and more attentions are paid to the institution inside the enterprise since The Nature of the Firm (by Ronald H. Coase, 1937) is published.

\subsection{Applicability of SCP Paradigm in This Study}

This section attempts to testify that public project, which is the object of this study, meets the four requirements above simultaneously. The result of this research will be not reliable when lack of this work.

1) SCP paradigm aims at an individual industry, then which industry should be analyzed using it in this study? Industry is defined as a group of enterprises sharing some important characters, while the key point is which character is selected to be the basis for enterprises classification. Therefore, we apply SCP paradigm to the agency industry of public project in this study. Concretely speaking, we classify the enterprises according to their customer and production, i.e., agency industry of public project provides construction management service and even operation management service of construction projects for the government principal. So a project management company belongs to the agency industry of public project only if it is attending or going to attend a public project as the agent of the government. The enterprises in this industry take full responsibility for their own profits and losses and they trade with the government principal and the enterprises of other industries as Figure 2 shown.

2) It is obvious that the enterprises in the agency industry of public project are project management companies and they are all stable contractual organizations. Since the agency industry of public project exists for public project and project management companies are the agents of public project only when they are involved in public projects. Therefore, whether its market is steady depends on the market of public project. Although public project, which is the core of its market, is temporary organization involving a series of contracts and the construction of a public project is short-term and one-off, demand of the public for public goods/services is persistent and it is the government's basic function to meet these demands. This means the demand and supply of public goods/services (which have to be realized by public projects) are both long -term and steady, and this also means there must 


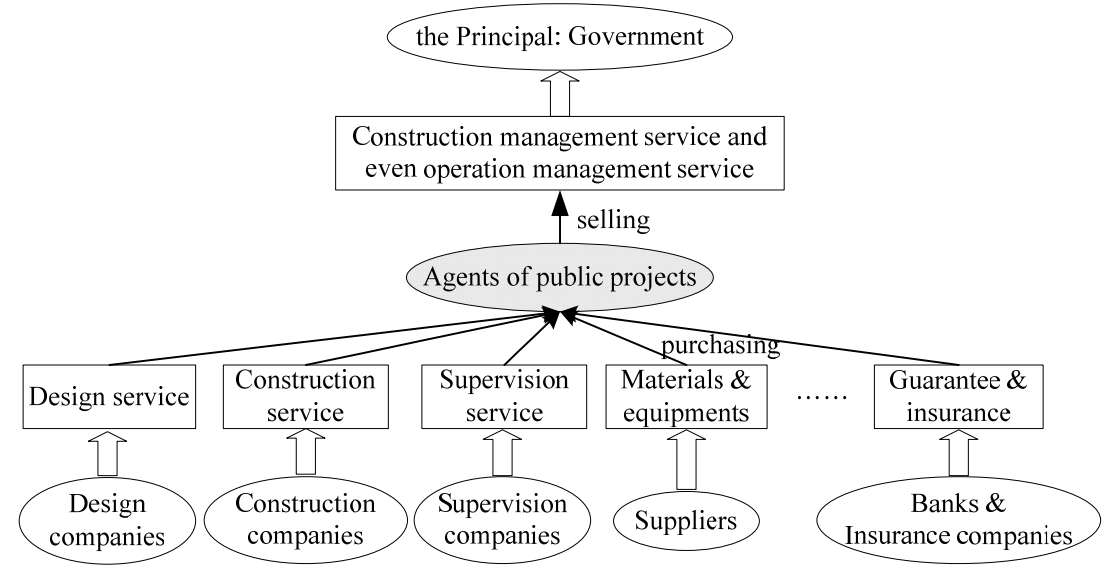

Figure 2. Trades by the enterprises in the agency industry of public project.

be a great many public projects need to be done by the government in succession. According to the analysis above, the market of public project is steady, so is the market in which the agency industry of public project exists.

3) To the enterprises in the agency industry of public project, their customer is the government and they have to take charge of the public projects involved with substantive capital, many stakeholders and great expectation of the public instead of the government. Therefore this industry undoubtedly will be guided by the government through related policies. Take construction-agent system (CAS for short, which is advocated to be applied to non-profit government investment projects in China) for example, the local governments made various laws and regulations to ensure better performance of the pubic project according to their actual situation, including the entry permission and elimination regulations for the construction agents, the implementation details of bidding for the construction agent, and the contract templates for construction commission. Take another striking example, the most popular PPP (Public Private Partnership) option for infrastructure projects in China is BOT (Build - Operate - Transfer) in which the private partner undertakes to finance, design, construct, operate and maintain the facility during a concession period that is usually determined by their public counterpart, in return, the private partner will recover their capital investment through the operation revenue over the concession period [34]. To ensure the commonweal - goal of the BOT projects, the government usually regulates the price of the public goods and/or services through the contract between them and relevant regulations. Moreover, the fact that every city constitutes an abun- dance of laws and regulations for public project indicates the significance of the government's policies in the agency industry of public project.

4) This research aims at exploring a fundamental thinking in order to help the government improve the management performance of public projects. The government, which is the sponsor of public projects, purchases relevant service from the agent and it is separated from the professional PM activities completely. What the government concern are two things, i.e., the relationship among the key stakeholders and the result of the public project (concretely speaking, the input-output relationship). It's necessary to regard the agent of the public project as a black box when the government focuses on the relationship among the key stakeholders, especially the contractual relationship between the government and the agent. Because it goes against the analysis of public project if the government pays too much attention to the issue within the agent. Figure 3 indicates that this research keeps outside the agent of the public project but has opened the black box of the public project. On the other hand, it's necessary to regard the agent of the public project as a black box when the government concerns the input-output relationship (in which the input of the public project is the capital, institutional arrangement and so on that the government has offered to the agent, while the output of the public project mainly is the project product, its effect on people's life and so on that the agent was going to deliver to the government) only. Because the inputoutput relationship is absolutely independent of the detail of the agent's PM process. Thus it can be seen that the agent of public project should be considered as a black box changing the input into the output. 


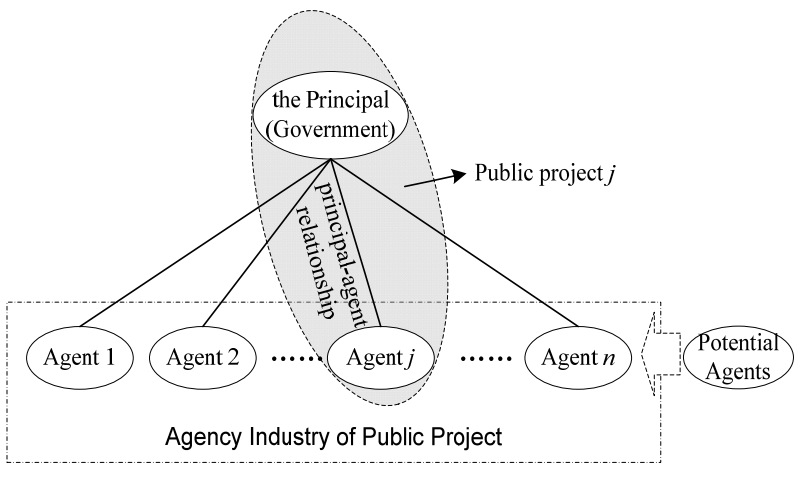

Figure 3. Public projects and its agency industry.

\section{Analysis and Findings}

\subsection{Primary Establishment of GMP Framework}

From what has been analyzed above, SCP paradigm can be used in the agency industry of public project. Considering the object of this research is not the agency industry of public project but the public project into which the agent is included, we must define the content of S, C and $P$ respectively.

\subsubsection{PG Corresponding to $S$}

In SCP paradigm, market structure (S) is defined as the characteristic of various relationships, such as the relationship among the sellers, the relationship among the buyers, the relationship between the group of sellers and the group of buyers and the relationship between the enterprises in the market and the potential enterprises planned to enter the market. It is conceptualized in terms of both economic and cognitive factors in practice. While what market structure (S) correspond to in this research?
The agents of public project and all the organizations trade with them compose the market we are going to focus on. Figure 2 and Figure 3 indicates that this market involves a series of relationships, including the relationship among the agents of public project, the relationship between the government and the agents, the relationship between the agent and the design companies/construction companies/supervision companies/suppliers/banks/insurance companies, and the relationship between the agents in the market and the potential agents planned to enter the market. Obviously, the market of the agency industry of public project involves the relationships among all the key stakeholders in a public project, which just is the object of PG.

Government governance and corporate governance are the polar cases of state- and private-ownership, while public project governance is the hybrid or alliance forms of them [35]. So their content is completely different although they share the same essence. Public project governance can be broke down into governance structure and governance mechanism, the former is the frame defining the contractual relationships of the key stakeholders in a project and the latter is the means to deal with the contractual incompleteness. So governance structure focuses on allocating the rights, especially residual rights of control and residual claimancy; while governance mechanism (shown as Figure 4 [36]) aims at harmonizing the key stakeholders using various governance tools. Essentially speaking, both governance structure and governance mechanism are dealing with the relationship among the key stakeholders, especially the relationship between the government and the agent of public project. The result of PG is establishing a set of institutional system with some unique characteristics, and

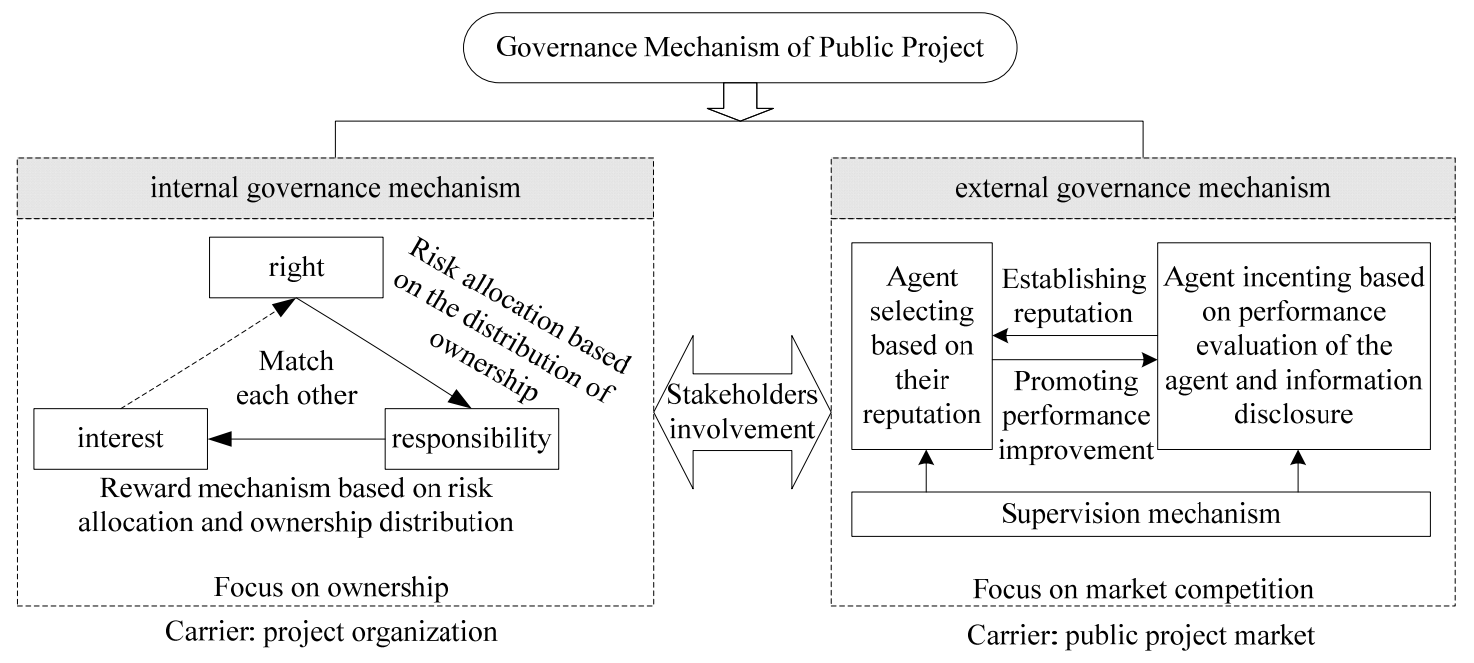

Figure 4. Content of governance mechanism in public project. 
this is consistent with the content of market structure (S) in the agency industry of public project. Considering the result of PG originats from its process, we think that in this research PG corresponds to market structure (S) in SCP paradigm.

\subsubsection{PM Corresponding to $\mathrm{C}$}

SCP paradigm states that firm conduct (C) is various decision-making behaviors taken by the enterprise fully considering the supply-demand relationship and the relationship between other enterprises and itself in order to win more profit and market share. As to the agency industry of public project, the economic activities of the enterprises are not producing and selling product but providing relevant service for the government, so firm conduct (C) of this industry is various decision-making behaviors taken by the enterprises fully considering the requirement of the government and the relationship between other enterprises and itself in order to get more interests at present and even in the future. The interests here include not only the income of a public project but also the intangibles such as a better reputation and keeping the agent qualification. Concretely speaking, the decision-making behaviors taken by the agent of public project include inviting public bidding for the design companies/construction companies/supervision companies/suppliers, setting goal/planning/implementing in each stage, managing the risk in the project, managing the human resource and their communication in the PM team and so on. Obviously, these are just consistent with the content of PM (shown in Table 2). Therefore, we suggest that in this research PM corresponds to firm conduct (C) in SCP paradigm.

\subsubsection{PPMP Corresponding to $P$}

In SCP paradigm, market performance $(\mathrm{P})$ denotes the result of a series of firm conduct under a certain market structure. It measures the running efficiency of the whole market and the state of its resource allocation. To ascertain the content corresponding to market performance $(\mathrm{P})$ in this research, three aspects should be taken into account:

1) According to its definition, market performance $(P)$ measures not the running efficiency of an individual enterprise but that of the whole market.

2) To the agency industry of public project, the result of the enterprises' conduct is the project product and the effect of the enterprises' conduct on the environment, society, people's life and so on. These are the content of traditional PPMP. Obviously, the observation point of this study should be in the end of the PM process. PPMP here includes the result part of generalized PPMP merely, while the process part of generalized PPMP is consistent with PM.
3) In Industrial Economics, market performance is usually discussed from the perspective of the consumers, and the consumers of the agency industry of public project are the governments. Therefore, we should analyze PPMP defined above on the standpoint of the government.

In a word, what market performance (P) in SCP paradigm corresponds to is the traditional PPMP (the result part of generalized PPMP) of all the public projects in the market on the standpoint of the government.

\subsubsection{Adjusting and Summarizing}

After defining the corresponding content of SCP paradigm's three components in this research, we get a primary fundamental thinking for public project analysis, i.e., Governance-Management-Performance (GMP) framework. However, GMP framework can be applied only to the collectivity of public projects in the market as a result of its evolvement from SCP paradigm. Can GMP framework be used in an individual public project? We insist that SCP paradigm has to be applied to the whole market due to the impartibility of market structure (S). While public project governance $(G)$ can denotes not only governance of the whole public project market but also governance of individual project (as shown in Table 2). Since public project governance $(G)$ which corresponds to market structure (S) can describe both the macroscopic level and the microcosmic level, PPMP (P) which corresponds to market performance $(\mathrm{P})$ certainly can denote both the performance of the whole public project market and the performance of an individual public project.

From what has been analyzed above, we can come to the conclusion as follows:

1) Scope of application: GMP framework can be applied to both the whole public project market and an individual public project.

2) Explanation of GMP framework (shown in Figure 5): Public project governance $(G)$ has positive effect on public project management $(\mathrm{M})$, and then public project management makes for better public project management performance $(\mathrm{P})$.

3) Its standpoint: GMP framework is a fundamental thinking for the analysis of public project and it is developed for the government to improve the management performance of public project.

It is obvious that GMP framework is consistent with the opinion of Xi Youmin [16] that corporate governance influences corporate management and its performance greatly to a great extent and the idea of Yan Ling [20] that PG can contribute to PPMP via PM. Moreover, GMP framework is also accord with the basic idea of institu- 


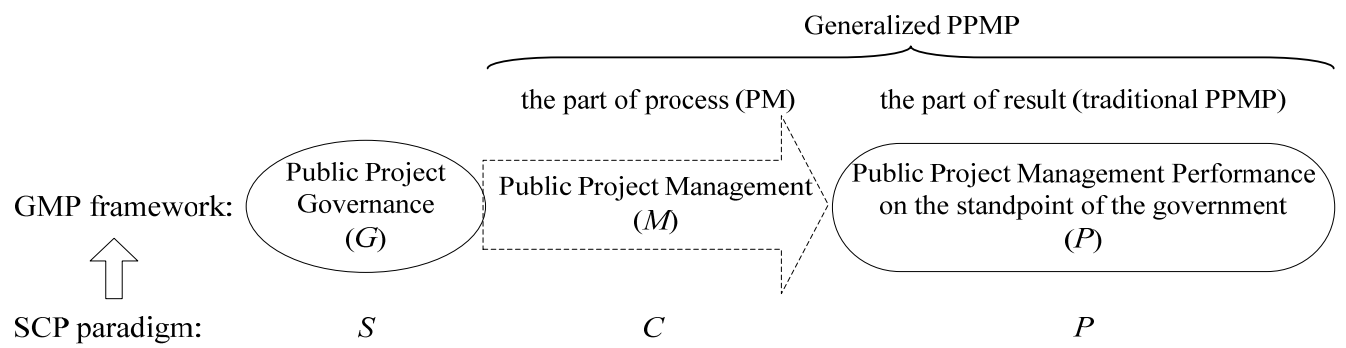

Figure 5. A fundamental thinking for improving the management performance of public projects.

tional Economics that institution ${ }^{2}$ works on economic behavior and economic performance and is the fundamental motivation of economy development.

\subsection{Theoretical Analysis of GMP Framework}

The preceding sub-section applies SCP paradigm to the agency industry of public project so as to get a fundamental thinking for improving management performance of public project, i.e., GMP framework. The main purpose of this step is to testify the reliability of GMP framework theoretically. So it will be broken down into three parts $(\mathrm{G} \rightarrow \mathrm{M}, \mathrm{M} \rightarrow \mathrm{P}$ and $\mathrm{G} \rightarrow \mathrm{P})$ and the effect mechanism of each part will be explored briefly.

\subsubsection{Effect of PG on PM}

The analysis of $\mathrm{G} \rightarrow \mathrm{M}$ is to answer how PG works on PM. Xi Youmin and Zhao Zengyao [16] claim that corporate governance defines the institution system for the transaction, under which corporate management drives the corporate to the set goal. The comparison of PG and $\mathrm{PM}$ in the literature review shows that so does the public project. Based on this fact, we insist that PG optimizes PM through its three basic functions, i.e., incenting, restricting and harmonizing (shown in Figure 6).

1) The function of incenting

The success of a public project depends on not only the exogenous variables which are uncontrollable, what is more important is the effort degree of the agent which is controllable. So it is significant for the government to incent the agent of the public project who implements PM instead of it. In this study, the agent incenting in public project is classified as reward incenting, incenting through sharing residual rights of control and residual claimancy and reputation incenting. Each of them has its strongpoint and weakness: reward incenting only has a distinct short-term effectiveness and is inclined to lead the agent to opportunistic behaviors; incenting through sharing residual rights of control and residual claimancy

\footnotetext{
${ }^{2}$ As said in the last section, the result of PG is establishing a set of institutional system.
}

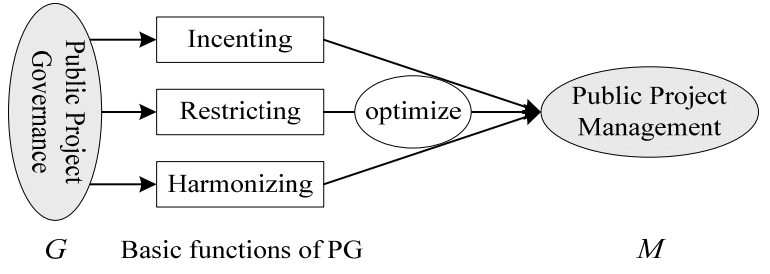

Figure 6. Effect of PG on PM.

can make the government and the agent interest community so as to urge the agent work hard for the government, but it is difficult to make the residual rights of control and residual claimancy be distributed symmetrically in public project because of its commonweal-goal; reputation incenting is a recessive mechanism with long-term effectiveness, but it relies on the highly developed public project market. In a word, the function of incenting deals with the motivation of the agent in order to enhance its working enthusiasm and exert its potential abilities fully, then PM can be optimized to a great extent.

2) The function of restricting

Restricting always goes together with incenting for they supplement each other. So the government also has to restrict the agent. In this study, the agent restricting in public project is classified as direct restricting and indirect restricting. The former includes the laws and regulations that are constituted by the government to define the due PM behaviors for the agents and the supervision to the agents by the government and the public. The latter means that the government creates some threats to urge the agent to select the PM behaviors that is advantageous to the government. It includes transferring some risks to the agent, adding some punishment measures in the contract, eliminating the incompetent agent form the public project market and disclosing the information about the agent. In a word, the function of restricting deals with the moral hazard problems of the agent; it makes the PM behaviors of the agent canonical in order to avoid the agent's deviation from the goal of the public project.

3) The function of harmonizing 
In view of its essence (see Table 2), harmonizing is the core function of PG. Strictly, the ultimate purpose of incenting and restricting is harmonizing. We insist that the harmonizing function of PG includes harmonizing the stakeholders' interests, goals and behaviors. All of the three level harmonizing can reduce conflicts and uncertainties in the process of PM so as to establish order in the public project and make the process of PM smooth.

In addition, $\mathrm{G} \rightarrow \mathrm{M}$ can be proved in another way. It is well known that the level of PM depends on two aspects successively: first, the inherent competence of the PM team for the public project, this is determined by the mechanism of agent selecting which is an important part of PG; second, to what extent the agent exert its competence in the public project, this is determined by the incenting and restricting to the agent which includes the rest contents of PG. Both the two aspects are determined by PG, so the level of PM depends on PG indeed.

\subsubsection{Effect of PM on PPMP}

It is proved through a thorough literature review that PM performance can be directly affected by PM greatly. Moreover, a mass of practices indicate that efficient PM can enhance PM performance $30 \%$ or more [37]. In this case, how does PM realize its positive effect on PM performance? Figure 5 illustrates that P in GMP framework indicates the result part of generalized PPMP and M in GMP framework indicates the process part of generalized PPMP. Therefore, the analysis of $\mathrm{M} \rightarrow \mathrm{P}$ is to answer how to transform PM behaviors into relevant results more effectively. We believe that PM performance is come true through the four basic functions of PM, i.e., planning, organizing, leading and controlling (shown in Figure 7). It is obvious that the functions of PM are the same as the functions of management. However, their difference is that the resources of a project are those needed in the transaction and available, such as capital, time, technology, personnel and facility [38]. In a word, $\mathrm{PM}$ team, i.e., the agent of the public project, can make the best use of everything through the four basic functions of PM so that it can get a better result, i.e., PM performance, for the government at last.

\subsubsection{Effect of PG on PPMP}

GMP framework which is obtained through the employment of SCP paradigm in the agency industry of public project indicates that there is no direct effect of PG on PPMP. This sub-section will argue its validity from two aspects:

1) Analysis from the characteristic of PG

It is analyzed above that the result of PG is establishing a set of institutional system, including the institutional environment in the macroscopic level and a well

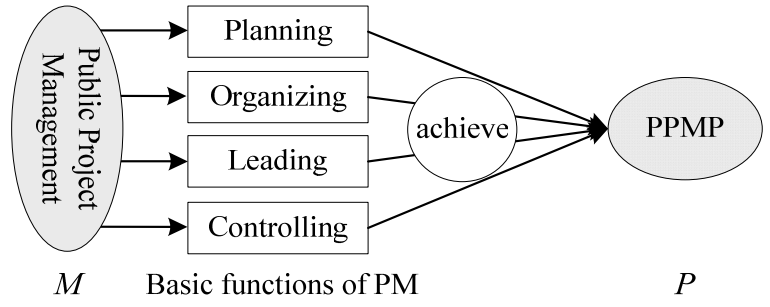

Figure 7. Effect of PM on PPMP.

order in the microcosmic level. The institution itself is a kind of productivity; proper institutional framework can reduce the conflicts and uncertainties but doesn't have any function of producing [39]. So it can only create performance via management behaviors.

2) Analysis from the assignation and utilization of resources

Project is not only a way of managing resource butalso a way of allocating resource. It is pointed out that PG deals with the secondary assignation of resource that follows the assignation by the market and PM deals with the further allocation of resources on the basis of PG framework and their effective utilization [16]. It is comprehensible that there will be no performance if we allocate the resources but don't utilize them.

According to the analysis above, no matter how perfect the PG is, the project is impossible to be completed, let alone PM performance, if the agent doesn't carry out $\mathrm{PM}$, such as planning and controlling its schedule, cost and quality. Therefore, PG can't work on PPMP directly; it can only contribute to the improvement of PPMP via PM.

\subsection{Validation of the Research Results}

Based on the analysis above, we get a fundamental thinking for improving PPMP, i.e., Governance - Management - Performance (GMP) framework. It indicates that the PPMP is a consequence of both PM and PG and PG is a more radical driver for PPMP improvement than PM. The findings also can be extended to:

1) According to the confirmed relationship of Governance $\rightarrow$ Management $\rightarrow$ Performance in public project, PPMP is the consequence of both PM and PG. Therefore, the public project must have any defect in its PG or PM if its management performance is not very well.

2) The confirmed relationship of Governance $\rightarrow$ Management $\rightarrow$ Performance in public project also indicates that there are two approaches to improve PPMP, namely PG and PM. The forepassed studies on PPMP improvement are dominated by the approach of PM. While, in this study, the positive effect of PG on 
PPMP is testified thoroughly and the complementarity of the fire-new viewpoint, i.e., PG, and the original viewpoint, i.e., PM, so acutely emerges.

3) GMP framework implies that PG is of overriding importance to PPMP, so the government may pay more attention to it. Take China for example, the central government began a push of government investment system reformation since 2004 and CAS is advocated to be applied to nonprofit government investment projects to improve their performance. Even nowadays, there are still many problems existing in the practices of CAS. The central government of China is increasingly conscious of the fact that PG is more effective than PM in China at present due to its vast development space.

\section{To Improve PPMP Using GMP Framework}

According to GMP framework, the government has two distinct ways to improve the management performance of public projects.

1) Optimizing PM

PM is to managing scope, project organization, quality, cost, time procurement, information, and in order to deliver the beneficial change desired by the owner [40]. Strictly speaking, PPMP is the result of PM and PM is the process of making PPMP. So it is comprehensible that good PM leads to good PPMP.

2) Optimizing PG

GMP framework indicates that PG can contribute to the improvement of PPMP via PM. As pointed out above, public project governance can be broken down into governance structure and governance mechanism and the characters of their contents are distinct. The former is relatively steady and it should match with the context and feature of the public project, while the latter is more flexible and it can be modified in a certain public project if needed. Governance mechanism attaches itself to some certain governance structure. Therefore, the governments have two approaches to improve PPMP based on PG:

- Selecting a proper governance structure (existing one or original one) for the public project at the beginning. There are many factors should be considered, such as the feature of the project, the context, the requirement of the owner and so on.

- Evaluating and then heightening the level of governance mechanism under a certain governance structure in the process of the public project. We should make certain the key evaluation indicators and the approach to evaluate. Finding the aspect of PG which has limitation and taking appropriate improving measures.

\section{Conclusions}

This study is not an attempt to improve PPMP completely in management paradigm or economics paradigm as the studies before. It aims at presenting and testifying a fundamental thinking for improving PPMP based on its formation mechanism. To this end, thorough literature review and theoretical analysis were carried out to identify two groups of factors affecting PPMP greatly, i.e. PG and PM, and then SCP paradigm is applied to the agency industry of public project to get GMP framework which is the critical contribution of this study. GMP framework reveals all the driving factors in the process of PPMP formation and improvement and their priority. Therefore, it will be a powerful tool for public project analysis and may help the government to improve PPMP further. Another contribution is the approach undertaken in this study. GMP framework is evolved from SCP paradigm which is a hypothesis in the traditional theory of Industrial Organization and the agency industry of public project is presented and chosen to be the object of SCP paradigm. It is an original attempt to get the conclusion about public project from the analysis of the agency industry of public project.

Limitations are unavoidable although extensive efforts were taken into this study. The most important one is that our conclusion is not based on the actual data of public project but comes from theoretical analysis merely. It is the important subject of our future research to testify GMP framework empirically. In fact, we are in the process of gathering certain actual data (including abundant data that reflect PM, PG and PPMP respectively) of construction-agent project in China at present although it is really a hard work. A sophisticated statistical analysis using structural equation modeling (SEM) will be carried out when enough data is collected and it will be the most convincing proof of GMP framework. In a word, this research is at its infancy and it requires more effort from those involved in this field.

\section{Acknowledgements}

This study is based on a research project funded by National Natural Science Foundation of China (NSFC) (No. 70772058/G0213), and, of course, appreciation and gratitude for providing other types of support for this study are extended to our colleagues in Institute of Public Project \& Cost Engineering (IPPCE), Tianjin University of Technology.

\section{REFERENCES}

[1] R. B. Denhardt, “Theories of Public Organization," Brooks/Cole Publishing Co., Monterey, California, 1984. 
[2] The Central People’s Government of the People's Republic of China. http://www.gov.cn/ztzl/kdnx/content_1145092. htm

[3] National Development and Reform Commission, Beijing, China. http://www.sdpc.gov.cn/xwzx/Xwtt/t20090306_264928.htm

[4] National Bureau of Statistics of China, Beijing, China. http://www.stats.gov.cn/tjsj/ndsj/

[5] Y. H. Fu and Y. L. Xu, "Performance Management," Fudan University Press, Shanghai, 2003 (in Chinese).

[6] R. Atkinson, "Project Management: Cost, Time and Quality, Two Best Guesses and a Phenomenon, its Time to Accept Other Success Criteria,” International Journal of Project Management, Vol. 17, No. 6, 1999, pp. 337343.

[7] K. N. Jha and K. C. Iyer, "Commitment, Coordination, Competence and the Iron Triangle,” International Journal of Project Management, Vol. 25, No. 5, 2007, pp. 527540.

[8] J. D. Bryde, "Modelling Project Management Performance,” International Journal of Quality \& Reliability Management, Vol. 20, No. 2, 2003, pp. 229-254.

[9] V. T. Luu, S.-Y. Kim and T.-A. Huynh, "Improving Project Management Performance of Large Contractors Using Benchmarking Approach,” International Journal of Project Management, Vol. 26, No. 7, 2008, pp. 758-769.

[10] E. Westerveld, “The Project Excellence Model $®$ : Linking Success Criteria and Critical Success Factors," International Journal of Project Management, Vol. 21, No. 6, 2003, pp. 411-418.

[11] F. Y. Y. Ling, S. P. Low, S. Q. Wang and H. H. Lim, "Key Project Management Practices Affecting Singaporean Firms's Project Performance in China,” International Journal of Project Management, Vol. 27, No. 1, 2009, pp. 59-71.

[12] A. K. Munns and B. F. Bjerimi, "The Role of Project Management in Achieving Project Success," International Journal of Project Management, Vol. 14, No. 2, 1996, pp. 81- 87.

[13] X. L. Zhang, "Comparative Study on the Government Performance Evaluation Methods in Foreign Countries," Soft Science (in Chinese), Vol. 18, No. 5, 2004, pp. 1-4.

[14] Y. L. Du and Y. L. Yin, “Critical Factors Affecting Management Performance of Enterprise Agent Construction Projects in China,” In: Proceedings International Conference on Engineering Management and Service Sciences (EMS 2009), Beijing, 20-22 September 2009.

[15] Y. L. Yin and Y. L. Du, "Magement Performance Improvement of Public Project: A New Perspective on Research Paradigm Shifting," Science \& Technology Progress and Policy (in Chinese), in Press.

[16] Y. M. Xi and Z. Y. Zhao, "Corporate Governance," Higher Education Press, Beijing, 2004 (in Chinese).

[17] J. R. Turner, “Towards a Theory of Project Management:
The Nature of the Project Governance and Project Management,” International Journal of Project Management, Vol. 24, No. 2, 2006, pp. 93-95.

[18] J. R. Turner and A. Keegan, "The Versatile Project-Based Organization: Governance and Operational Control,” European Management Journal, Vol. 17, No. 3, 1999, pp. 296-309.

[19] G. M. Winch, "Governing the Project Process: A Conceptual Framework," Construction Management and Economics, Vol. 19, No. 8, 2003, pp. 799-808.

[20] L. Yan and Y. L. Yin, "The Theory of Public Project Governance,” Publishing House of Tianjin University, Tianjin, 2006 (in Chinese).

[21] Y. L. Du, "Improvement of Public Project Management Performance Based on Project Governance,” Ph.D. Dissertation, Tianjin University, Tianjin, 2008 (in Chinese).

[22] PMI, "A Guide to the Project Management Body of Knowledge (PMBOK Guide),” 3rd Edition, Project Management Institute, Newton Square, 2004.

[23] R. Loo, "Training in Project Management: A Powerful Tool for Improving Individual and Team Performance," Team Perform Manage: An International Journal, Vol. 2, No. 3, 1996, pp. 6-14.

[24] F. T. Anbari, C. N. Bredillet and J. R. Turner, "Perspectives on Research in Project Management," Academy of Management Proceedings, Philadelphia, 2008.

[25] K. X. Sha, "From Management to Governance: Analysis of Evolution of the Theory of Construction Projects," Construction Economy (in Chinese), No. 6, 2008, pp. 12-14.

[26] B. Li, A. Akintoye, P. J. Edwards and C. Hardcastle, "The Allocation of Risk in PPP/PFI Construction Projects in the UK," International Journal of Project Management, Vol. 23, No. 1, 2005, pp. 25-35.

[27] R. L. K. Tiong and J. Alum, "Evaluation of Proposals for BOT Projects," International Journal of Project Management, Vol. 15, No. 2, 1997, pp. 67-72.

[28] L. Yan and Y. L. Yin, "Management Performance Improvement of Agent System for Government Invested Construction Projects,” China Civil Engineering Journal (in Chinese), Vol. 39, No. 11, 2006, pp. 120-126.

[29] W. A. Li, "Study on corporate Governance Evaluation and its Index,” Higher Education Press, Beijing, 2005 (in Chinese).

[30] M. J. Rui, “Industrial Economics,” Shanghai University of Finance and Economics Press, Shanghai, 2005 (in Chinese).

[31] G. Panagiotou, "The Impact of Managerial Cognitions on the Structure-Conduct-Performance (SCP) Paradigm: A Strategic Group Perspective,” Management Decision, Vol. 44, No. 3, 2006, pp. 423-441.

[32] Z. Y. Liu, “A Course in Modern Industrial Economics,” Science Press, Beijing, 2007 (in Chinese).

[33] X. F. Niu, "Theory of Industrial Organization and Researches on the Related Problem," China Economics Pub- 
lishing House, Beijing, 2004 (in Chinese).

[34] S. T. Ng, J. Z. Xie, Y. K. Cheung and M. Jefferies, “A Simulation Model for Optimizing the Concession Period of Public-Private Partnerships Schemes,” International Journal of Project Management, Vol. 25, No. 8, 2007, pp. 791-798.

[35] W. J. Henisz, "Governance Issues in Public Private Partnerships,” International Journal of Project Management, Vol. 24, No. 7, 2006, pp. 537-538.

[36] Y. L. Yin, Y. L. Du, L. Yan and Z. Wei, "Continuous Improvement of Public Project Management Performance Based on Project Governance,” In: Proceedings of the 4th IEEE International Conference on Wireless Communications, Networking and Mobile Computing: Engineering,
Services and Knowledge Management (EMS), Washington, 15-17 October 2008

[37] J. R. Turner, “Contracting for Project Management," Gower Publishing Limited, Great Britain, 2003.

[38] Y. F. Lai, B. Xia and Q. Zhang, "Engineering Project Management,” Wuhan University Press, Wuhan, 2006 (in Chinese).

[39] W. Kasper and M. E. Streit, "Institutional Economics: Social Order and Public Policy,” Translated by C. H. Han, The Commercial Press, Beijing, 2003 (in Chinese).

[40] J. R. Turner, “Towards a Theory of Project Management: The Functions of Project Management," International Journal of Project Management, Vol. 24, No. 3, 2006, pp. 187-189. 